\title{
Study of Computational Theory of Surface Plasmon Resonance (SPR) for Porcine Gelatin Detected Sensor Based Nanomaterial $\mathrm{Fe}_{3} \mathrm{O}_{4}-\mathrm{CNT}$ in Otto's Configuration
}

\author{
Maulina Lutfiyah*, Asih Melati** \\ Physics Department, Faculty of Science and Technology, UIN Sunan Kalijaga Yogyakarta \\ Jl. Marsda Adisucipto No 1 Yogyakarta 55281, Indonesia. Tel. +62-274-540971, Fax. +62-274-519739. \\ Email: maulinalutfiyah@gmail.com*, asih.melati@gmail.com**
}

\begin{abstract}
Happyalita U C. 2017. Study of Computational Theory of Surface Plasmon Resonance (SPR) for Porcine Gelatin Detected Sensor Based Nanomaterial Fe ${ }_{3} \mathrm{O}_{4}-\mathrm{CNT}$ in Otto's Configuration. Proc Internat Conf Sci Engin 1: 115-124. Accurate biomolecular detection can be performed through the Surface Plasmon Resonance (SPR) phenomenon. This study was conducted to determine the effect of the addition of $\mathrm{Fe}_{3} \mathrm{O}_{4}$ and Carbon Nanotube (CNT) nanomaterials in the Otto configurations and their use as porcine detection sensors. The research was conducted theoretically by finding the equation of reflectance and computationally using Matlab software version 7.12.0 to know SPR angle and reflectance value. This research uses ATR method with Otto configuration. The modeling was finished using HeNe laser light on $632.8 \mathrm{~nm}$ wavelength, semi-circle prism type BK7, metal layer of gold nanoparticles. The results of the research can be used in the detection of porcine gelatin by Otto configurations. The best air gap thickness is $30 \mathrm{~nm}$. The best thickness of the gold layer and $\mathrm{Fe}_{3} \mathrm{O}_{4}$ layer are $50 \mathrm{~nm}$ and $0.05 \mathrm{~nm}$. The applied of MWCNT nanoparticles is not effective in the detection of biomolecules based SPR. While the thickness of SWCNT used is $1 \mathrm{~nm}$. The SWCNT material also proved to be better used in SPR systems. The addition of porcine gelatin layer in the system shows a graphic change in the form of increasing reflectance value and SPR angular shift.
\end{abstract}

Keywords: CNT, nanomaterial $\mathrm{Fe}_{3} \mathrm{O}_{4}$, porcine gelatin, $\mathrm{SPR}$

\section{INTRODUCTION}

The development of science and technology today is so fast that it requires the academics to continue to develop their knowledge in order to compete with the outside world. Moreover, we has entered the ASEAN free trade system (MEA). Market competition is also becoming more widespread. Currently, there are many studies that use biosensors because of the benefits in the field of excellent public service. According to the International Union of Pure and Applied Chemistry (IUPAC), biosensors are tools or analytical devices that use certain biochemical reactions mediated by enzymes, immunosystems, tissues, organelles, or isolated cells to detect chemical mixtures with outputs of electrical signals, heat, or optics. The biosensor system can be developed through Surface Plasmon Resonance (SPR) phenomenon. SPR equipment system will assist the development of technology both in the field of health, medicine, and in industry. Biosensor system on SPR is expected to be used as a halal detection sensor of a product. Halalism of a product both medicine and food is now a major concern among the public, especially in Indonesia, which is predominantly Muslim. Based on the Halal Journal (Kuala Lumpur), in the past 10 years the world's halal food market is worth about 632 billion dollars annually. The world's halal food market value is equivalent to $16 \%$ of the total food industry worldwide based on Time magazine calculations. Indonesia, which has a majority Muslim population, should have a role in developing the halal market. Not just to show the existence of the state and take market opportunities, but more focused to protect the population from consuming something that is unlawful. Therefore, Indonesia should be able to guarantee the halalness of domestic industrial products and ensure halal products imported from abroad.

In the Holy Qur'an Surah Al-Maidah verse 3, it is clearly stated that eating carrion, blood, and pig is haram. However, some rogue producers provide a mixture of porcine gelatins on their products. To qualify halal a drug and food, it must be free from porcine gelatin content. The content of porcine gelatins in a processed product such as gelatin is very difficult to know directly. Gelatin from different sources has very similar physical and chemical properties that are difficult to distinguish. The differences of each type of gelatin can be determined from the amino acid composition. Therefore, it takes a tool that is able to detect the presence of porcine gelatin content in a product. Seeing this, halal detection of a SPR-based product is very necessary to be developed. This research will be conducted theoretically computation using Matlab 7.12.0 software. The simulation of SPR-based biosensor system that will be developed is using $\mathrm{Fe}_{3} \mathrm{O}_{4}$ and CNT nanomaterials. This study tried to test computationally to know the phenomenon of SPR that happened in biosensor nanomaterial $\mathrm{Fe}_{3} \mathrm{O}_{4}$ and CNT as detection of porcine gelatin. 


\section{Surface Plasmon Resonance}

Surface Plasmon Resonance (SPR) is a physical process that occurs when polarized light shoots / irradiates a metal film under internal reflection conditions. The SPR was preceded by the peculiarities that occurred during 1902-1912 Wood shone polarized light on a metal behind a diffraction grating. A dark and bright band pattern is seen in reflected light. However, at that time Wood had not found a good answer to explain the event. (Schasfoort and Tudos, 2008; Arifin, 2010)

It was then described by Rayleigh in 1907. In his work, "Dynamical Theory of the Gratings" which became the basis for the development of electromagnetic field scattering. He concluded that the scattering of the field is the single wavelength, each corresponding to the spectral sequence arising from the lattice. Then he observed this wavelength, which was then called the Rayleigh wavelength $\left(\lambda_{R}\right)$, which matched the Wood anomaly (Arifin, 2009). SPR can occur in the metallic / dielectric boundary field when a beam of light comes from a dielectric medium with a larger angle coming from a critical angle (Sigh, 2014). In such conditions, in the boundary plane of the dielectric / metal divergence there will be evanescent waves penetrating into the metal medium. If the resonance condition is met, resonance between the evanescent wave and the free electrons occurs on the metal surface resulting in a local electric field and a much larger penetration of the evanescent wave. (Homola, 2006; Sambles, 1991)

The SPR phenomenon results in a reduction in the intensity of light passing through the prism, depending on the type and thickness of the material used. When light enters the prism, some light is reflected and partially transmitted. Prisms coated with materials with a certain index of refraction allow the light to continue, and possibly no waves. The free electrons in the metal have electromagnetic waves inside them. The movement of electromagnetic waves inside the metal surface is called surface plasmon. Whereas plasmons are the quantized oscillations of electrons in a conductive medium. In quantum concepts, plasmons are often regarded as quasi particles similar to the concept of photons and phonons (Ru and Etchegoin, 2009). When the surface plasmon has the same properties as the light wave is forwarded then appears Surface Plasmon Resonance (SPR). The intensity of light reflected back from the surface of the magnitude differs from the surface. This intensity can be measured to determine when the SPR occurs (Kooyman, 2007).

The dispersion relation between $\mathrm{k}$ and $\omega$ becomes close $\sqrt{\varepsilon_{2} \omega} / c$ when $\mathrm{k}_{\mathrm{x}}$ is very small because of the limit $\omega \rightarrow 0, \varepsilon_{1} \gg \varepsilon_{2}$. As for the big $\mathrm{k}$ moment

$$
\varepsilon_{1}^{\prime}+\varepsilon_{2}=0
$$

For metal simple layer, dielectric constant is given by plasmon frequency $\omega_{\mathrm{p}}$

$$
\varepsilon_{1}^{\prime}=1-\frac{\omega_{p}^{2}}{\omega^{2}}
$$

From equation (1) and (2), frekuensi surface plasmon $\omega_{\mathrm{sp}}$ can define as

$$
\omega_{s p}=\omega_{p} \frac{1}{\sqrt{1+\varepsilon_{2}}}
$$

In terms of wave propagation in free space, the number of waves will be proportional to the frequency. In other words, this wave propagation dispersion curve is a linear curve. However, the EC wave dispersion curve is not linear. From that figure, it is clear that there is no intersection between the free wave dispersion curve and the EC wave dispersion curve, ie the $K_{i x}=K_{s p}$ condition has never occurred. (Yamamoto, 2008)

The EC phenomenon cannot be observed simply by illuminating a metal / dielectric boundary field. Therefore, it is necessary to make a way for both curves to intersect. One way that can be done is to use a prism so that the light wave dispersion curve can be changed to the slope and produce a intersection with the $\mathrm{EC}$ wave dispersion curve. When the wave of light comes in total internal reflection, the evanescent wave spreads on the boundary plane of the dielectric / dielectric layer with the wave vector (Arifani and Abraha, 2013).

$$
k_{x}=\left(\frac{\omega}{c} n_{p}\right) \sin \theta_{i}
$$

In order for the dispersion curve to intersect $\left(K_{i x}=K_{s p}\right)$, the angle of light must meet

$$
\sin \theta_{i}=\frac{1}{n_{p}} \sqrt{\frac{\varepsilon_{d} \varepsilon_{m}}{\varepsilon_{d}+\varepsilon_{m}}}
$$

Along the boundary plane equal to surface plasmon wave vector (SP). The SP wave vector is determined only by the dielectric constant of the metal and the dielectric material, given by the relationship with $\mathrm{gm}$ is the metal dielectric constant and $\varepsilon_{d}$ is the dielectric constant of the dielectric material. ( $\mathrm{Wu}, 2010)$

The SP wave vector is determined only by the dielectric constant of the metal and the dielectric material, given by the relationship with $\varepsilon_{d}$ and $\varepsilon_{m}$, so the above equation can also be written as follows,

$$
K_{s p}=\frac{\omega}{c} \sqrt{\frac{\varepsilon_{d} \varepsilon_{m}}{\varepsilon_{d}+\varepsilon_{m}}}=\left(\frac{2 \pi}{\lambda}\right) \sqrt{\frac{\varepsilon_{d} \varepsilon_{m}}{\varepsilon_{d}+\varepsilon_{m}}}
$$

The reflectance intensity for the 3 layer system (prism, metal, and medium) in the Kretschmann configuration based on the Fresnel formula for the ppolarization is shown by the following equation, 


$$
\begin{gathered}
R=\left|\frac{r_{p r 1}+r_{12} e^{2 i K_{z i d i}}}{1+r_{p r 1} r_{12} e^{2 i K_{z i d i}}}\right|^{2} \\
r_{i j}=\left(\frac{K_{z i}}{\varepsilon_{i}}-\frac{K_{z j}}{\varepsilon_{j}}\right) /\left(\frac{K_{z i}}{\varepsilon_{i}}+\frac{K_{z j}}{\varepsilon_{j}}\right) \\
K_{z i}=\frac{2 \pi}{\lambda}\left(\varepsilon_{i}-n_{p}^{2} \sin ^{2} \theta\right)^{\frac{1}{2}}
\end{gathered}
$$

With $r_{i j}$ denoting the reflectance coefficients at the intermediate $\mathrm{i}$ and $\mathrm{j}$ medium interfaces, $K_{z i}$ shows the perpendicular surface wave vector components, $d_{i}$ and $\varepsilon_{i}$ $(i=1,2,3)$ are the thickness and the dielectric constant of the medium to -i. (Jahanshahi, 2015)

When light is radiated on a prism with a thin layer of gold $(50 \mathrm{~nm})$, the reflectance of light approaches zero at an angle to the prism where surface plasmon waves on the gold surface are coupled with some light coming. This angle is called the SPR angle and is very sensitive to the thickness of the sample layer. SPR is highly dependent on the nature of the thin metal layer, the wavelength of light occurring and the refractive index of the medium on the other side of the thin metal layer (Yan et al, 2013). The metal has electrons in the conduction band that can resonate with the light coming on suitable light waves. Metals suitable for this condition are silver, gold, aluminum, sodium, copper and indium. The metal on the sensor surface must be free of oxidation, sulphide, and does not react with other molecules contained in air and water ( $\mathrm{Ru}$ and Etchegoin, 2009; Oliveira et al., 2015). The weaknesses of the metal are too expensive indium, too reactive sodium, copper and aluminum are too coarse in response to SPR, and silver is too susceptible to oxidation so that the most suitable metal is gold. Gold is very resistant to oxidation and other atmospheric pollution.

\section{Atteuated Total Reflection}

The approach to understanding surface plasmon excitation can use the Attenuated Total Reflection (ATR) method. There are two configurations of the ATR method of Kretschmann and Otto configurations. In the Otto configuration, the dielectric layer is between the prism and the metal layer or there is an air gap between the metal layer prisms. Light comes from the prism and then enters the air and dielectric layers to produce evanescent waves in the dielectric / metal boundary layer. SPR waves form on the boundary plane if the above resonance conditions are met. (Arifin, 2009; Otto, 1968)

\section{Nanoparticle $\mathrm{Fe}_{3} \mathrm{O}_{4}$}

Magnetic nanoparticles are magnetic materials of nanometer size. Magnetic nanoparticles have varying physical and chemical properties and can be applied in various fields. One such magnetic particle that can be nanometer-sized is iron oxide such as $\mathrm{Fe}_{3} \mathrm{O}_{4}$ (magnetite). $\mathrm{Fe}_{3} \mathrm{O}_{4}$ can be utilized as a material that helps in drug transport systems (Drug Delivery System), Magnetic Resonance Imaging (MRI), and cancer therapy. The $\mathrm{Fe}_{3} \mathrm{O}_{4}$ magnetic nanoparticles can also be used as Surface Plasmon Resonance (SPR) based biosensors. The $\mathrm{Fe}_{3} \mathrm{O}_{4}$ magnetic nanoparticles as active ingredients in SPR biosensors serve to detect DNA (deoxyribonucleic acid) quickly and sensitively (Sari, 2012). To be applicable in these areas, it is important to consider the particle size, magnetic properties, and surface properties of the nanoparticles themselves. Figure 2.10 is a powder of $\mathrm{Fe}_{3} \mathrm{O}_{4}$ nanoparticles and $\mathrm{Fe}_{3} \mathrm{O}_{4}$ molecular structure. The $\mathrm{Fe}_{3} \mathrm{O}_{4}$ nanoparticles may be superparamagnetic. These properties make $\mathrm{Fe}_{3} \mathrm{O}_{4}$ able to interact with biomolecules. The detection of biomolecules with $\mathrm{Fe}_{3} \mathrm{O}_{4}$ material is done through the SPR phenomenon. The presence of biomolecules is known by the change of SPR angle. This change is caused by changes in refractive index on metal interfaces and dielectrics (Husain, 2012). Some property values of $\mathrm{Fe}_{3} \mathrm{O}_{4}$ when subjected to $\mathrm{HeNe}$ laser light with a wavelength of $632.8 \mathrm{~nm}$ have a refractive index $(\mathrm{n}=$ $2.162+1.178$ i). (Sari, 2012)

\section{Carbon Nanotube}

Carbon Nanotube (CNT) is one of carbon structure that is shaped like cylinder with diameter in nanometer order. One of the uniqueness in this structure is its advantages in terms of strength, electrical properties, and also properties in good heat conduction. CNT is formed with the ratio of length: width is 132.000.000: 1 , bigger than other material. This carbon cylinder molecule is very useful in the field of nanotechnology, electronics, optics and various fields of materials science and technology.

Carbon nanotubes include one of the fullerene structural members. The name carbon nanotube comes from its long, hollow shape with a wall formed by a sheet of one atom of carbon thick, called graphene. This carbon sheet is rolled up at a discrete and angle. The chemical bonds of CNTs are formed from sp2 bonds similar to graphite. This bond is stronger than the sp3 bond found in alkanes and diamonds. CNTs are categorized into two types ie single-walled or SWCNT and many-walled (MWCNT). SWCNT has electrical properties not owned by the MWCNT structure. This allows the development of SWCNT structures into nanowires because SWCNT can be a good conductor. In addition SWCNT has been developed as a substitute for Field Effects Transistors (FET) on a nano scale. This is because SWCNT properties can be nFETs as well as pFET when reacting to oxygen. Since it can have properties as n-FET and p-FET then SWCNT can function as a logic gate. CNTs can be conductor and also semiconductor. When a CNT as a conductor, it can have a very high conductivity of up to 1 billion Ampere per 1 $\mathrm{cm} 2$. CNTs have an electrical current density of 1000 times greater than metal (eg copper, silver). CNTs have the ability to transmit $6000 \mathrm{~W} / \mathrm{m} \mathrm{/} \mathrm{K}$ at room temperature (at copper only $385 \mathrm{~W} / \mathrm{m} / \mathrm{K}$ ). In addition, the nanotubes remain stable to $2800{ }^{\circ} \mathrm{C}$ in a vacuum and 
about $750^{\circ} \mathrm{C}$ in free air. CNTs have some very useful optical or feeding properties. The optical properties of MWCNT and SWCNT have some differences. Based on its chemical structure, MWCNT has optical properties similar to graphite (Djurisic, 1999) whereas SWCNT is similar to carbon (Phillip, 1964) so that optical properties of CNTs are obtained through both approaches.

Table 1. Optical properties of CNT on wavelength $632,8 \mathrm{~nm}$.

\begin{tabular}{lll}
\hline Optical properties & MWCNT & SWCNT \\
\hline Refractive index $(\mathrm{n})$ & 2,8363 & 2,4015 \\
Wave number(k) & 1,5944 & 0,0000 \\
Dielectric constant $(\varepsilon)$ & $5,5024+9,044 i$ & $5,8106+0,0000 i$ \\
Absorption coefficient $(\alpha)$ & $3,1662 \times 10^{5}$ & 0,0000 \\
/cm & \\
\hline
\end{tabular}

\section{Porcine Gelatin}

Gelatin is a protein derivative of collagen fibers present in the skin, bones, and cartilage. The amino acid structure is almost similar to collagen, where glycine is the main amino acid and constitutes $2 / 3$ of all the amino acids that make up it, the remaining $1 / 3$ of the amino acid is filled by proline and hydroxyproline. The average molecular weight of gelatin ranges from 15,000 250,000. Water-soluble gelatin, acetic acid and alcohol solvents such as glycerol, propylene glycol, sorbitol and mannitol, but not soluble in alcohols, acetone, carbon tetrachloride, benzene, petroleum ether and other organic solvents. (Islamiah, 2016)

Gelatin has reversible properties that can change from sole to gel form, swell or expand in cold water, can form film, affect the viscosity of a material, and can protect colloidal system. The properties of the gelatin surfaces are based on the fact that the gelatin side chains, like other proteins, have a charged group and a particular part of the collagen chain contains hydrophobic and hydrophilic amino acids. Hydrophobic and hydrophilic parts can move on the surface, thereby reducing the facial stresses of the solution. At the same time, gelatin has several properties to protect the stability of the formed surface. The multifunctional properties of this gelatin are used in the production and stabilization of foams and emulsions.

Gelatin is naturally present in bones or animal skins such as; fish, beef and porcine gelatin. Gelatin derived from mammals is more widely used in food production because it has high melting point, good gelling agent and reversible thermo. Gelatin obtained from porcine gelatins is the most widely used gelatin in the food and medicine industry, considering the gelatin obtained from these animals is the least expensive compared to other animals. In the food industry, gelatin is used as a raw material for making soft candy, jelly, ice cream, formula, bread, processed meat, milk and soup mixed drinks. In the drug industry gelatin is used as one of the raw materials for making vaccine, capsule shell, pill, cream, toothpaste, soap and rubbing (Puspitaningrum, 2015). Gelatin preparation is an attempt to utilize bone waste that is usually unused and disposed of in slaughterhouses. The use of gelatin in the food industry is primarily intended to overcome the problems that arise especially in product diversification.

The gelatin of each animal species can be distinguished by its amino acid content and chemical structure. Figure 2.14 shows the chemical structure of porcine gelatin. Physically, the difference of amino acid content can be known through the difference of refractive index. Gelatin refractive index can be obtained through SPR phenomenon where the bigger angle of SPR shift, the greater the refractive index of a gelatin. The index of refractive porcine gelatin through SPR phenomena with wavelength of $632.8 \mathrm{~nm}$ laser light is 1.3351 (Wardani, 2012).

\section{MATERIALS AND METHODS}

This research is conducted in theoretical computation so that the tools and materials used are very simple, namely: computer with Windows 7 operating system which has installed software Matlab 7.12.0 with license number 161052 and application of winspall version 3.02 and stationery. This research procedure consists of 2 main parts namely the determination of the reflectance equation and the SPR curve making. The obtained equation is then used in the manufacture of SPR curves using Matlab 7.12.0 software. Modeling is done by using ATR method with Otto configuration. The data taken using Matlab software version 7.12.0 in the form of reflectance value for each variation of angle shown in graphical form of relationship between the coming angle with the reflectance value. Graphs obtained will be analyzed and compared to graphs created using the Winspall 3.02 application for Windows. Winspall is one application designed to simulate SPR curves based on Fresnel equations. In this program only need to include the value of material thickness and relative permittivity.

\section{RESULTS AND DISCUSSION}

This research is conducted theoretically and computationally. Theoretical research is finished by studying optical properties when Plasmon Resonance Surface (SPR) occurs. The main requirement of the resonance is when the plasmon frequency is equal to the frequency of the incident light. To find out the SPR angle that occurs need to know also the value of reflectance. The reflectance value is influenced by the type of material. SPR modeling is done by ATR method (Attenuated Total Reflection) so that the used is the reflectance value not the transmission value. In this research, will be conducted theoretical and computational studies with Otto configuration. In Otto configuration, the system created has at least 4 layers because in this configuration there is a air gap that lies between the prism and the metal layer. 


\section{Theoritical Study}

a. Four layer system (prism, air gap, gold, air)

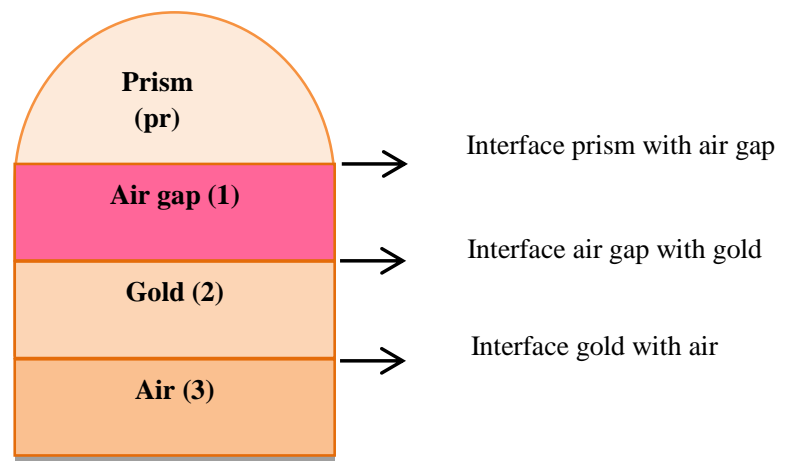

Figure 1. The modeling of optical system of SPR in 4 layers.

$$
\begin{aligned}
& R=\left|r_{p r 123}\right|^{2}=\left|\frac{r_{p r 1}+r_{123} e^{2 i K_{z 1} d_{1}}}{1+r_{p r 1} r_{123} e^{2 i K_{z 1} d_{1}}}\right|^{2} \\
& r_{p r 1}=\frac{\left(\cos \theta / n_{p r}\right)-\left(\varepsilon_{1}-n_{p r}^{2} \sin ^{2} \theta\right)^{1 / 2} / \varepsilon_{1}}{\left(\cos \theta / n_{p r}\right)+\left(\varepsilon_{1}-n_{p r}^{2} \sin ^{2} \theta\right)^{1 / 2} / \varepsilon_{1}} \\
& r_{12}=\frac{\left(\varepsilon_{1}-n_{p r}^{2} \sin ^{2} \theta\right)^{1 / 2} / \varepsilon_{1}-\left(\varepsilon_{2}-n_{p r}^{2} \sin ^{2} \theta\right)^{1 / 2} / \varepsilon_{2}}{\left(\varepsilon_{1}-n_{p r}^{2} \sin ^{2} \theta\right)^{1 / 2} / \varepsilon_{1}+\left(\varepsilon_{2}-n_{p r}^{2} \sin ^{2} \theta\right)^{1 / 2} / \varepsilon_{2}} \\
& r_{23}=\frac{\left(\varepsilon_{2}-n_{p r}^{2} \sin ^{2} \theta\right)^{1 / 2} / \varepsilon_{2}-\left(\varepsilon_{3}-n_{p r}^{2} \sin ^{2} \theta\right)^{1 / 2} / \varepsilon_{3}}{\left(\varepsilon_{2}-n_{p r}^{2} \sin ^{2} \theta\right)^{1 / 2} / \varepsilon_{2}+\left(\varepsilon_{3}-n_{p r}^{2} \sin ^{2} \theta\right)^{1 / 2} / \varepsilon_{3}} \\
& r_{123}=\frac{r_{12}+r_{23} e^{2 i K_{z 2} d_{2}}}{1+r_{12} r_{23} e^{2 i K_{z 2} d_{2}}} \\
& K_{z 1} d_{1}=\frac{\omega}{c} d_{1}\left(\varepsilon_{1}-n_{p r}^{2} \sin ^{2} \theta\right)^{1 / 2} \\
& K_{z 2} d_{2}=\frac{\omega}{c} d_{2}\left(\varepsilon_{2}-n_{p r}^{2} \sin ^{2} \theta\right)^{1 / 2}
\end{aligned}
$$

Note:

\footnotetext{
$\mathrm{R} \quad$ = reflectance

$\mathrm{r}_{\mathrm{ij}} \quad=$ reflectance coefficient on medium interface $i$ and medium $j$

$\varepsilon_{I}=$ dielectric constant of material $i$

$\mathrm{n}_{\mathrm{pr}}=$ refractive index of prism

$\mathrm{Kz}_{\mathrm{i}}=$ wave vector component that perpendicular with interface

$\mathrm{d}_{\mathrm{i}} \quad=$ thickness of material $i(\mathrm{~nm})$

$\theta \quad=$ angle of incindence $\left({ }^{\circ}\right)$

c $\quad=$ light velocity $\left(\mathrm{m} / \mathrm{s}^{2}\right)$
}

b. Five layer system (prism, air gap, gold, nanomaterial $\mathrm{Fe} 3 \mathrm{O} 4$, air)

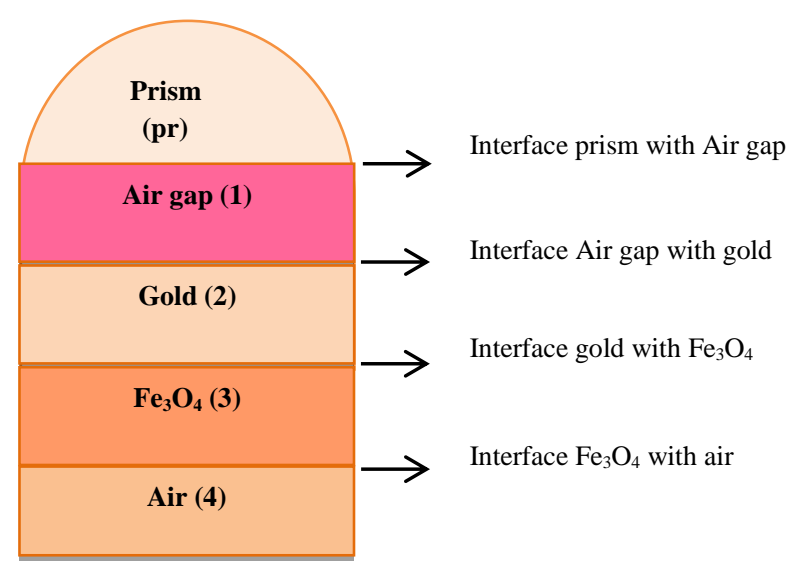

Figure 2. The modeling of optical system of SPR in 5 layers.

$$
\begin{aligned}
& R=\left|r_{p r 1234}\right|^{2}=\left|\frac{r_{p r 1}+r_{1234} e^{2 i K_{z 1} d_{1}}}{1+r_{p r 1} r_{1234} e^{2 i K_{z 1} d_{1}}}\right|^{2} \\
& r_{p r 1}=\frac{\left(\cos \theta / n_{p r}\right)-\left(\varepsilon_{1}-n_{p r}^{2} \sin ^{2} \theta\right)^{1 / 2} / \varepsilon_{1}}{\left(\cos \theta / n_{p r}\right)+\left(\varepsilon_{1}-n_{p r}^{2} \sin ^{2} \theta\right)^{1 / 2} / \varepsilon_{1}}
\end{aligned}
$$

$r_{12}=\frac{\left(\varepsilon_{1}-n_{p r}^{2} \sin ^{2} \theta\right)^{1 / 2} / \varepsilon_{1}-\left(\varepsilon_{2}-n_{p r}^{2} \sin ^{2} \theta\right)^{1 / 2} / \varepsilon_{2}}{\left(\varepsilon_{1}-n_{p r}^{2} \sin ^{2} \theta\right)^{1 / 2} / \varepsilon_{1}+\left(\varepsilon_{2}-n_{p r}^{2} \sin ^{2} \theta\right)^{1 / 2} / \varepsilon_{2}}$

$r_{23}=\frac{\left(\varepsilon_{2}-n_{p r}^{2} \sin ^{2} \theta\right)^{1 / 2} / \varepsilon_{2}-\left(\varepsilon_{3}-n_{p r}^{2} \sin ^{2} \theta\right)^{1 / 2} / \varepsilon_{3}}{\left(\varepsilon_{2}-n_{p r}^{2} \sin ^{2} \theta\right)^{1 / 2} / \varepsilon_{2}+\left(\varepsilon_{3}-n_{p r}^{2} \sin ^{2} \theta\right)^{1 / 2} / \varepsilon_{3}}$

$r_{34}=\frac{\left(\varepsilon_{3}-n_{p r}^{2} \sin ^{2} \theta\right)^{1 / 2} / \varepsilon_{3}-\left(\varepsilon_{4}-n_{p r}^{2} \sin ^{2} \theta\right)^{1 / 2} / \varepsilon_{4}}{\left(\varepsilon_{3}-n_{p r}^{2} \sin ^{2} \theta\right)^{1 / 2} / \varepsilon_{3}+\left(\varepsilon_{4}-n_{p r}^{2} \sin ^{2} \theta\right)^{1 / 2} / \varepsilon_{4}}$

$r_{234}=\frac{r_{23}+r_{34} e^{2 i K_{23} d_{3}}}{1+r_{23} r_{34} e^{2 i K_{23} d_{3}}}$

$r_{1234}=\frac{r_{12}+r_{234} e^{2 i K_{z 2} d_{2}}}{1+r_{12} r_{234} e^{2 i K_{z 2} d_{2}}}$

$$
K_{z 1} d_{1}=\frac{\omega}{c} d_{1}\left(\varepsilon_{1}-n_{p r}^{2} \sin ^{2} \theta\right)^{1 / 2}
$$

$$
K_{z 2} d_{2}=\frac{\omega}{c} d_{2}\left(\varepsilon_{2}-n_{p r}^{2} \sin ^{2} \theta\right)^{1 / 2}
$$

$$
K_{z 3} d_{3}=\frac{\omega}{c} d_{3}\left(\varepsilon_{3}-n_{p r}^{2} \sin ^{2} \theta\right)^{1 / 2}
$$


c. Six layer system (prism, air gap, gold, nanomaterial $\mathrm{Fe} 3 \mathrm{O} 4, \mathrm{CNT}$, air)

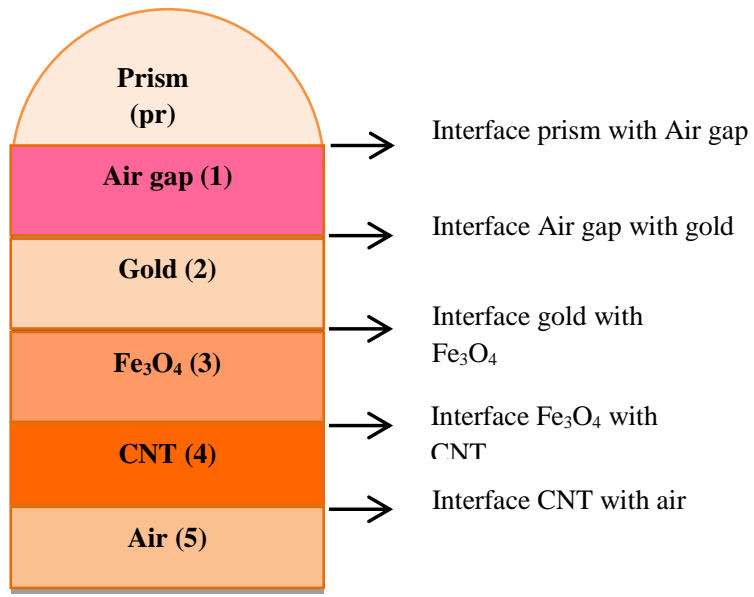

Figure 3. The modeling of optical system of SPR in 6 layers.

$$
\begin{aligned}
& R=\left|r_{p r 12345}\right|^{2}=\left|\frac{r_{p r 1}+r_{12345} e^{2 i K_{z 1} d_{1}}}{1+r_{p r 1} r_{12345} e^{2 i K_{z 1} d_{1}}}\right|^{2} \\
& r_{p r 1}=\frac{\left(\cos \theta / n_{p r}\right)-\left(\varepsilon_{1}-n_{p r}^{2} \sin ^{2} \theta\right)^{1 / 2} / \varepsilon_{1}}{\left(\cos \theta / n_{p r}\right)+\left(\varepsilon_{1}-n_{p r}^{2} \sin ^{2} \theta\right)^{1 / 2} / \varepsilon_{1}} \\
& r_{12}=\frac{\left(\varepsilon_{1}-n_{p r}^{2} \sin ^{2} \theta\right)^{1 / 2} / \varepsilon_{1}-\left(\varepsilon_{2}-n_{p r}^{2} \sin ^{2} \theta\right)^{1 / 2} / \varepsilon_{2}}{\left(\varepsilon_{1}-n_{p r}^{2} \sin ^{2} \theta\right)^{1 / 2} / \varepsilon_{1}+\left(\varepsilon_{2}-n_{p r}^{2} \sin ^{2} \theta\right)^{1 / 2} / \varepsilon_{2}}
\end{aligned}
$$$$
r_{23}=\frac{\left(\varepsilon_{2}-n_{p r}^{2} \sin ^{2} \theta\right)^{1 / 2} / \varepsilon_{2}-\left(\varepsilon_{3}-n_{p r}^{2} \sin ^{2} \theta\right)^{1 / 2} / \varepsilon_{3}}{\left(\varepsilon_{2}-n_{p r}^{2} \sin ^{2} \theta\right)^{1 / 2} / \varepsilon_{2}+\left(\varepsilon_{3}-n_{p r}^{2} \sin ^{2} \theta\right)^{1 / 2} / \varepsilon_{3}}
$$$$
r_{34}=\frac{\left(\varepsilon_{3}-n_{p r}^{2} \sin ^{2} \theta\right)^{1 / 2} / \varepsilon_{3}-\left(\varepsilon_{4}-n_{p r}^{2} \sin ^{2} \theta\right)^{1 / 2} / \varepsilon_{4}}{\left(\varepsilon_{3}-n_{p r}^{2} \sin ^{2} \theta\right)^{1 / 2} / \varepsilon_{3}+\left(\varepsilon_{4}-n_{p r}^{2} \sin ^{2} \theta\right)^{1 / 2} / \varepsilon_{4}}
$$$$
r_{45}=\frac{\left(\varepsilon_{4}-n_{p r}^{2} \sin ^{2} \theta\right)^{1 / 2} / \varepsilon_{4}-\left(\varepsilon_{5}-n_{p r}^{2} \sin ^{2} \theta\right)^{1 / 2} / \varepsilon_{5}}{\left(\varepsilon_{4}-n_{p r}^{2} \sin ^{2} \theta\right)^{1 / 2} / \varepsilon_{4}+\left(\varepsilon_{5}-n_{p r}^{2} \sin ^{2} \theta\right)^{1 / 2} / \varepsilon_{5}}
$$$$
r_{345}=\frac{r_{34}+r_{45} e^{2 i K_{z 4} d_{4}}}{1+r_{34} r_{45} e^{2 i K_{z 4} d_{4}}}
$$$$
r_{2345}=\frac{r_{23}+r_{345} e^{2 i K_{23} d_{3}}}{1+r_{23} r_{345} e^{2 i K_{23} d_{3}}}
$$

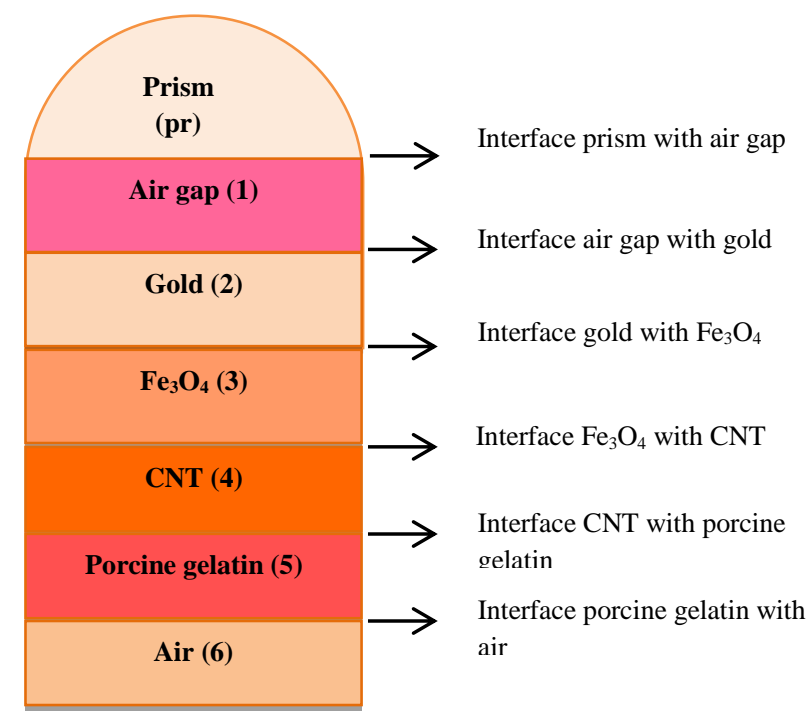

Figure 4. The modeling of optical system of SPR in 7 layers.

$$
\begin{aligned}
& R=\left|r_{p r 123456}\right|^{2}=\left|\frac{r_{p r 1}+r_{123456} e^{2 i K_{21} d_{1}}}{1+r_{p r 1} r_{123456} e^{2 i K_{z 1} d_{1}}}\right|^{2} \\
& r_{p r 1}=\frac{\left(\cos \theta / n_{p r}\right)-\left(\varepsilon_{1}-n_{p r}^{2} \sin ^{2} \theta\right)^{1 / 2} / \varepsilon_{1}}{\left(\cos \theta / n_{p r}\right)+\left(\varepsilon_{1}-n_{p r}^{2} \sin ^{2} \theta\right)^{1 / 2} / \varepsilon_{1}} \\
& r_{12}=\frac{\left(\varepsilon_{1}-n_{p r}^{2} \sin ^{2} \theta\right)^{1 / 2} / \varepsilon_{1}-\left(\varepsilon_{2}-n_{p r}^{2} \sin ^{2} \theta\right)^{1 / 2} / \varepsilon_{2}}{\left(\varepsilon_{1}-n_{p r}^{2} \sin ^{2} \theta\right)^{1 / 2} / \varepsilon_{1}+\left(\varepsilon_{2}-n_{p r}^{2} \sin ^{2} \theta\right)^{1 / 2} / \varepsilon_{2}} \\
& r_{23}=\frac{\left(\varepsilon_{2}-n_{p r}^{2} \sin ^{2} \theta\right)^{1 / 2} / \varepsilon_{2}-\left(\varepsilon_{3}-n_{p r}^{2} \sin ^{2} \theta\right)^{1 / 2} / \varepsilon_{3}}{\left(\varepsilon_{2}-n_{p r}^{2} \sin ^{2} \theta\right)^{1 / 2} / \varepsilon_{2}+\left(\varepsilon_{3}-n_{p r}^{2} \sin ^{2} \theta\right)^{1 / 2} / \varepsilon_{3}}
\end{aligned}
$$

d. Seven layer system (prism, air gap, gold, nanomaterial $\mathrm{Fe} 3 \mathrm{O} 4, \mathrm{CNT}$, porcine gelatin, air)

$r_{12345}=\frac{r_{12}+r_{2345} e^{2 i K_{z 2} d_{2}}}{1+r_{12} r_{2345} e^{2 i K_{z 2} d_{2}}}$

$K_{z 1} d_{1}=\frac{\omega}{c} d_{1}\left(\varepsilon_{1}-n_{p r}^{2} \sin ^{2} \theta\right)^{1 / 2}$

$K_{z 2} d_{2}=\frac{\omega}{c} d_{2}\left(\varepsilon_{2}-n_{p r}^{2} \sin ^{2} \theta\right)^{1 / 2}$$$
K_{z 3} d_{3}=\frac{\omega}{c} d_{3}\left(\varepsilon_{3}-n_{p r}^{2} \sin ^{2} \theta\right)^{1 / 2}
$$$$
K_{z 4} d_{4}=\frac{\omega}{c} d_{4}\left(\varepsilon_{4}-n_{p r}^{2} \sin ^{2} \theta\right)^{1 / 2}
$$

\section{ld,}

\section{.}


$r_{34}=\frac{\left(\varepsilon_{3}-n_{p r}^{2} \sin ^{2} \theta\right)^{1 / 2} / \varepsilon_{3}-\left(\varepsilon_{4}-n_{p r}^{2} \sin ^{2} \theta\right)^{1 / 2} / \varepsilon_{4}}{\left(\varepsilon_{3}-n_{p r}^{2} \sin ^{2} \theta\right)^{1 / 2} / \varepsilon_{3}+\left(\varepsilon_{4}-n_{p r}^{2} \sin ^{2} \theta\right)^{1 / 2} / \varepsilon_{4}}$

$r_{45}=\frac{\left(\varepsilon_{4}-n_{p r}^{2} \sin ^{2} \theta\right)^{1 / 2} / \varepsilon_{4}-\left(\varepsilon_{5}-n_{p r}^{2} \sin ^{2} \theta\right)^{1 / 2} / \varepsilon_{5}}{\left(\varepsilon_{4}-n_{p r}^{2} \sin ^{2} \theta\right)^{1 / 2} / \varepsilon_{4}+\left(\varepsilon_{5}-n_{p r}^{2} \sin ^{2} \theta\right)^{1 / 2} / \varepsilon_{5}}$

$r_{56}=\frac{\left(\varepsilon_{5}-n_{p r}^{2} \sin ^{2} \theta\right)^{1 / 2} / \varepsilon_{5}-\left(\varepsilon_{6}-n_{p r}^{2} \sin ^{2} \theta\right)^{1 / 2} / \varepsilon_{6}}{\left(\varepsilon_{5}-n_{p r}^{2} \sin ^{2} \theta\right)^{1 / 2} / \varepsilon_{5}+\left(\varepsilon_{6}-n_{p r}^{2} \sin ^{2} \theta\right)^{1 / 2} / \varepsilon_{6}}$

$r_{456}=\frac{r_{45}+r_{56} e^{2 i K_{55} d_{5}}}{1+r_{45} r_{56} e^{2 i K_{55} d_{5}}}$

$r_{3456}=\frac{r_{34}+r_{456} e^{2 i K_{z 4} d_{4}}}{1+r_{34} r_{456} e^{2 i K_{z 4} d_{4}}}$

$r_{23456}=\frac{r_{23}+r_{3456} e^{2 i K_{z 3} d_{3}}}{1+r_{23} r_{3456} e^{2 i K_{z 3} d_{3}}}$

$r_{123456}=\frac{r_{12}+r_{23456} e^{2 i K_{z 2} d_{2}}}{1+r_{12} r_{23456} e^{2 i K_{z 2} d_{2}}}$

$K_{z 1} d_{1}=\frac{\omega}{c} d_{1}\left(\varepsilon_{1}-n_{p r}^{2} \sin ^{2} \theta\right)^{1 / 2}$

$K_{z 2} d_{2}=\frac{\omega}{c} d_{2}\left(\varepsilon_{2}-n_{p r}^{2} \sin ^{2} \theta\right)^{1 / 2}$

$K_{z 3} d_{3}=\frac{\omega}{c} d_{3}\left(\varepsilon_{3}-n_{p r}^{2} \sin ^{2} \theta\right)^{1 / 2}$

$K_{z 4} d_{4}=\frac{\omega}{c} d_{4}\left(\varepsilon_{4}-n_{p r}^{2} \sin ^{2} \theta\right)^{1 / 2}$

$K_{z 5} d_{5}=\frac{\omega}{c} d_{5}\left(\varepsilon_{5}-n_{p r}^{2} \sin ^{2} \theta\right)^{1 / 2}$

\section{Computational Study}

Before the prism is coated with a metal material or object identifier, a simulation is made before empty prism to know the shape of the SPR curve when the prism is empty and look for the critical angle of the prism. Figure 5 is the result of simulating the relationship between reflectance to the angle of arrival when the prism is empty.

The simulation is made using prism BK7 with refractive index of 1.5151 . The results obtained using Matlab 7.12.0 software are similar to those of the Winspall 3.02 application. Based on the results obtained, it is known that when the empty prism increases the value of reflectance before the total reflection or TIR (Total Internal Reflection). TIR occurs when the reflectance value is 1 at angle $41.5^{\circ}$. This angle is called the critical angle, which means the refraction of the incident light with angle $90^{\circ}$. After the TIR the rays continue to reflect perfectly. In this system there is no SPR due to the absence of metal material so there is no surface plasmon wave.
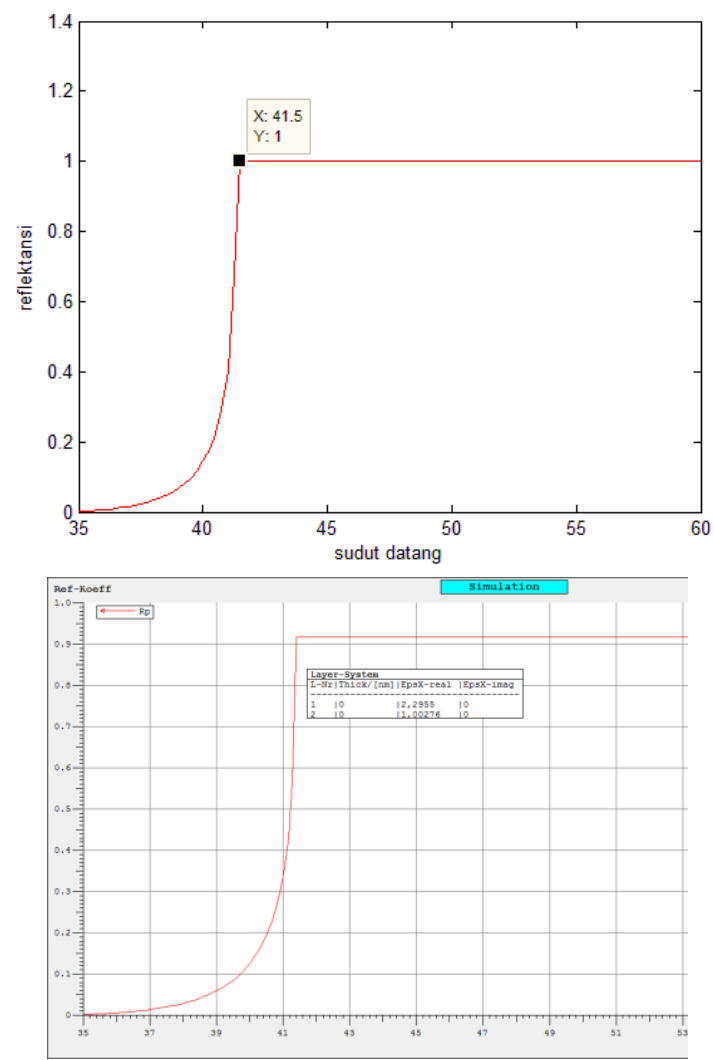

Figure 5. The reflectance graph of the angle comes when the prism is blank with software Matlab 7.12.0 (left) and the Winspall 3.02 app (right).

A computational study conducted to obtain a graph of the relationship between reflectance to the incident angle, from the graph can be seen the SPR angle value and its reflectance. This computational study was conducted in the following variations.

a. Four layer system (prism, air gap, gold, air) Variation water distance between gold with prism

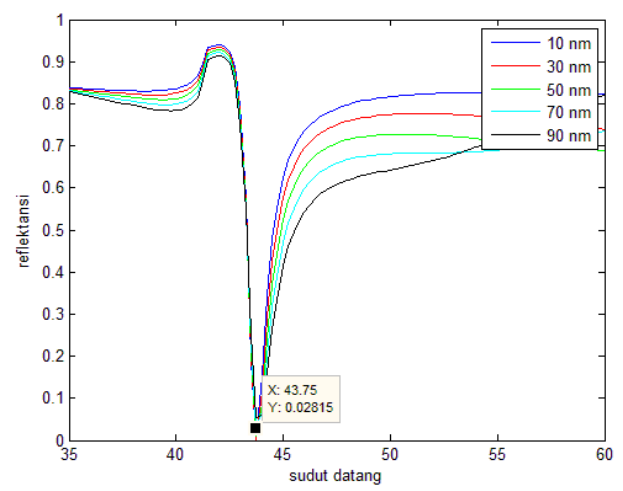

Figure 6. SPR graph on four layer system with variation of air thickness 
Table 2. Variation of air gap thickness.

\begin{tabular}{ccc}
\hline Thickness & SPR angle & Reflectance \\
\hline $10 \mathrm{~nm}$ & 43,75 & 0,001388 \\
$30 \mathrm{~nm}$ & 43,75 & 0,001256 \\
$50 \mathrm{~nm}$ & 43,75 & 0,01029 \\
$70 \mathrm{~nm}$ & 43,75 & 0,02815 \\
$90 \mathrm{~nm}$ & 43,75 & 0,05413 \\
\hline
\end{tabular}

SPR phenomenon with Otto configuration has a layout of at least 4 layers arranged with layers after the prism is a narrow air gap. Effective thickness of gap should be known to vary the thickness of air gap. Variations were performed at $10 \mathrm{~nm}, 30 \mathrm{~nm}, 50 \mathrm{~nm}, 70$ $\mathrm{nm}$, and $90 \mathrm{~nm}$ thicknesses. The best result is obtained at air thickness $30 \mathrm{~nm}$ with reflectance equal to 0,001256 and SPR angle equal to $43,7^{\circ}$. Thus it can be seen that the addition of air layer at $30 \mathrm{~nm}$ thickness can decrease the reflectance value than without the air gap (Kretschmann configuration). Air gap thickness also greatly affect the SPR phenomenon. Large air gap can result in the absence of SPR phenomenon.

b. Four layer system (prism, air gap, gold, air) with variation of gold thickness

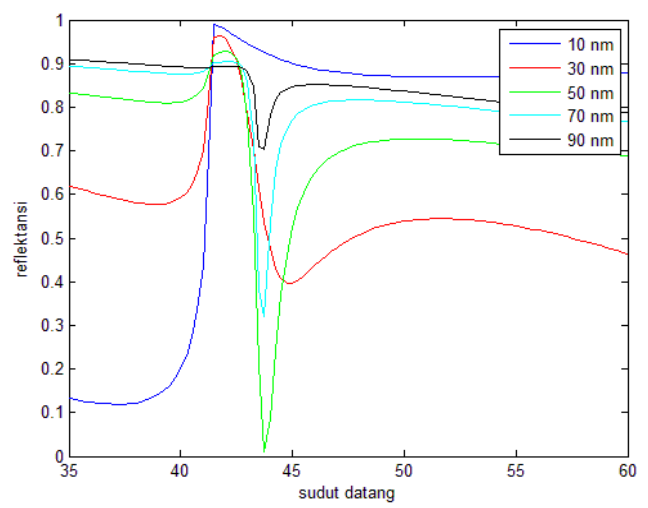

Figure 7. SPR graph on four layer system with variation of gold thickness.

Table 3. Variation thickness lapisan nanopartikel gold.

\begin{tabular}{ccc}
\hline Thickness & SPR angle & Reflectance \\
\hline $10 \mathrm{~nm}$ & There is no SPR & There is no SPR \\
$30 \mathrm{~nm}$ & 44,5 & 0,3663 \\
$50 \mathrm{~nm}$ & 43,75 & 0,001256 \\
$70 \mathrm{~nm}$ & 43,75 & 0,3701 \\
$90 \mathrm{~nm}$ & 43,75 & 0,7325 \\
\hline
\end{tabular}

In Otto 4-layer system configuration, in addition to variation of air gap thickness, also done variations in the thickness of the gold coating. This suggests that the addition of gold nanoparticles to the Otto configuration can also bring up surface plasmon waves. It can be seen from Figure 7 that there is a decrease in the reflectance value before the TIR. The lowest point or lowest peak is the SPR point where $K_{\text {surface plasmon is the same as }}$

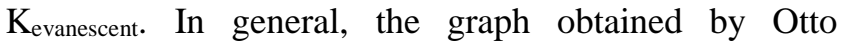
configuration the best gold coating thickness is at $50 \mathrm{~nm}$ thickness. Reflectance value at this system is equal to 0,001256 with SPR angle that is $43,75^{\circ}$. c. Five layer system (prism, gold, $\mathrm{Fe}_{3} \mathrm{O}_{4}$, air) with variation of $\mathrm{Fe}_{3} \mathrm{O}_{4}$ nanoparticles thickness

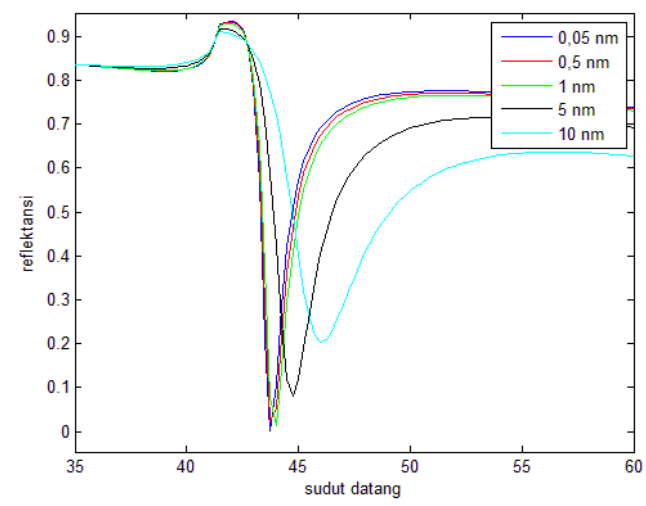

Figure 8. SPR graph on five layer system with variation of $\mathrm{Fe}_{3} \mathrm{O}_{4}$ thickness.

Table 4. Variation thickness nanopartikel $\mathrm{Fe}_{3} \mathrm{O}_{4}$ konfigurasi Otto.

\begin{tabular}{ccc}
\hline Thickness & SPR angle & Reflectance \\
\hline $0,05 \mathrm{~nm}$ & 43,75 & 0,001441 \\
$0,5 \mathrm{~nm}$ & 43,75 & 0,021800 \\
$1 \mathrm{~nm}$ & 44,00 & 0,012360 \\
$10 \mathrm{~nm}$ & 44,75 & 0,080350 \\
$50 \mathrm{~nm}$ & 46,00 & 0,202500 \\
\hline
\end{tabular}

The 5-layer system is made with a $30 \mathrm{~nm}$ air thickness, gold thickness of $50 \mathrm{~nm}$, and $\mathrm{Fe}_{3} \mathrm{O}_{4}$ thickness varied. Five variations of $\mathrm{Fe}_{3} \mathrm{O}_{4}$ thickness were observed as well as variations of $\mathrm{Fe}_{3} \mathrm{O}_{4}$ thicknesses in the Kretschmann configuration. The best thickness of $\mathrm{Fe}_{3} \mathrm{O}_{4}$ is used when the highest absorption is at $0.05 \mathrm{~nm}$ thickness with reflectance value of 0.001441 and SPR angle of $43.75^{\circ}$. The addition of the $\mathrm{Fe}_{3} \mathrm{O}_{4}$ nanoparticle layer in the Otto configuration can also decrease the reflectance value. The thicker layers of $\mathrm{Fe}_{3} \mathrm{O}_{4}$ nanoparticles occur right angle shifts and changes in reflectance values. The SPR angular shift shows that with the addition of layer thickness the refractive index value of the material also changes.

d. Six layer system (prism, air, gold, $\mathrm{Fe}_{3} \mathrm{O}_{4}, \mathrm{MWCNT}$, air) with variation of MWCNT thickness

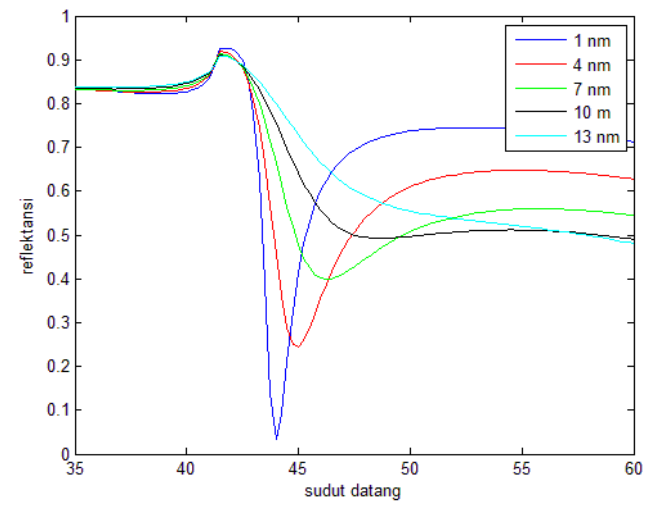

Figure 9. SPR graph on six layer system with variation MWCNT thickness. 
Table 5. Variation of MWCNT thickness.

\begin{tabular}{ccc}
\hline Thickness & SPR angle & Reflectance \\
\hline $1 \mathrm{~nm}$ & 44,00 & 0,03243 \\
$4 \mathrm{~nm}$ & 45,00 & 0,2446 \\
$7 \mathrm{~nm}$ & 46,25 & 0,3985 \\
$10 \mathrm{~nm}$ & 48,50 & 0,4922 \\
$13 \mathrm{~nm}$ & Without SPR & Without SPR \\
\hline
\end{tabular}

The 6-layer system is made using a 30nm air gap, a layer of gold nanoparticles with a thickness of $50 \mathrm{~nm}$, and the addition of $\mathrm{Fe}_{3} \mathrm{O}_{4}$ and CNT nanomaterials. The thickness of $\mathrm{Fe}_{3} \mathrm{O}_{4}$ used is $0,05 \mathrm{~nm}$. In this system, the type of CNT used is MWCNT. Variation of MWCNT thickness was done in 5 variations ie at thickness of 1 $\mathrm{nm}, 4 \mathrm{~nm}, 7 \mathrm{~nm}, 10 \mathrm{~nm}$, and $13 \mathrm{~nm}$. Based on these simulation results, the best SPR phenomenon graph is at a thickness of $1 \mathrm{~nm}$ MWCNT. The results obtained are reflectance values of 0.03243 and SPR angle $44^{\circ}$. In this configuration, when compared to a system without the addition of MWCNT, the results obtained an increase in reflectance value and a SPR angular shift to the right. The SPR angular shift indicates a change in refractive index in the system while the increase in reflectance value indicates that the reflected beam becomes larger.

e. Six layer system (prism, air, gold, $\mathrm{Fe}_{3} \mathrm{O}_{4}, \mathrm{SWCNT}$, air) with variation of SWCNT thickness

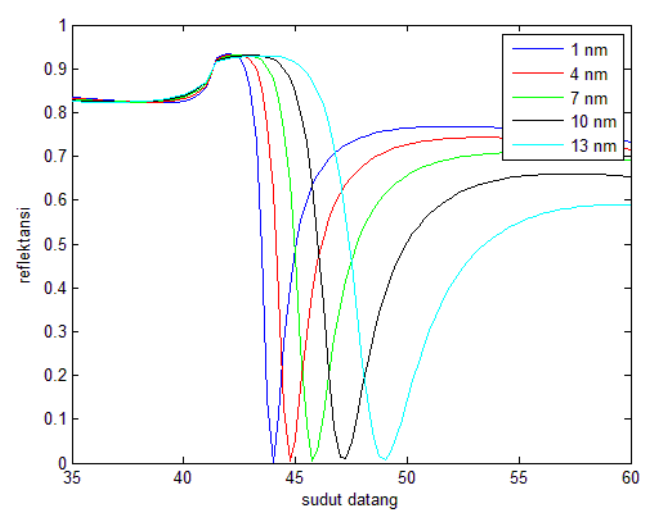

Figure 10. SPR graph with variation of SWCNT thickness.

Table 6. Variation thickness SWCNT konfigurasi Otto.

\begin{tabular}{ccc}
\hline Thickness & SPR angle & Reflectance \\
\hline $1 \mathrm{~nm}$ & 44,00 & 0,001317 \\
$4 \mathrm{~nm}$ & 44,75 & 0,003202 \\
$7 \mathrm{~nm}$ & 45,75 & 0,005257 \\
$10 \mathrm{~nm}$ & 47,25 & 0,009018 \\
$13 \mathrm{~nm}$ & 49,00 & 0,008737 \\
\hline
\end{tabular}

Simulation with 6 layer system created using SWCNT type. In this system also performed 5 variations of SWCNT thickness as in 6 layer system with MWCNT. Based on the research, it is found that the bigger the nanoparticle size the bigger the SPR shift angle. The reflectance value in each SWCNT thickness variation always changes (see table 6). The best SPR angle at a thickness of $1 \mathrm{~nm}$. When compared to the results before the addition of SWCNT, the results obtained showed a decrease in reflectance value and the SPR angular shift. This indicates that the addition of SWCNT has a positive effect in the SPR system.

f. Seven layer system (prism, air, gold, $\mathrm{Fe}_{3} \mathrm{O}_{4}$, SWCNT, porcine gelatin, air) with $\mathrm{Fe}_{3} \mathrm{O}_{4}$ and SWCNT for the detection of porcine gelatin

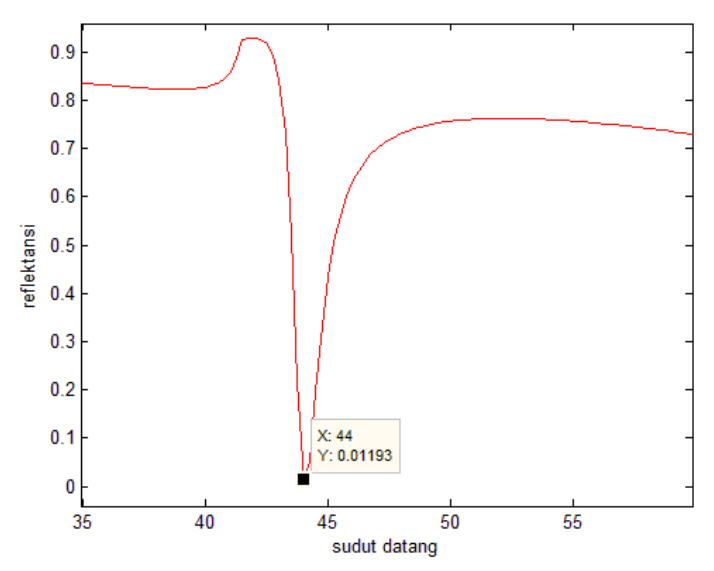

Figure 11. SPR graph konfigurasi Otto with penambahan nanopartikel SWCNT sebagai deteksi porcine gelatin.

SPR system simulation as a porcine gelatin detection sensor is also finished in Otto configuration. In this system, the thickness of Air gap used is $30 \mathrm{~nm}$, with a thickness of gold layer of $50 \mathrm{~nm}$. This study adds a layer of $0.05 \mathrm{~nm} \mathrm{Fe} \mathrm{O}_{4}$ nanoparticles as the active ingredient of biomolecule binder and CNT as sensitivity sensor enhancer. The type of CNT used is SWCNT because it has been proven from the simulation that the addition of SWCNT is more effective in the SPR system than the addition of MWCNT. Based on experimental results with the addition of SWCNT nanoparticles $1 \mathrm{~nm}$ obtained that no SPR angle shift is $44^{\circ}$ and the increase of reflectance value to 0,01193 . A considerable increase in reflectance indicates the presence of biomolecules. The addition of porcine gelatin biomolecules in the system makes the reflected rays more numerous. This system can be used to detect biomolecules with high sensitivity.

In the Otto configuration, the addition of $\mathrm{Fe}_{3} \mathrm{O}_{4}$ and CNT nanoparticles has the same properties as the Kretschmann configuration, but the reflectance value in the Otto configuration is smaller with an air-gap thickness of $30 \mathrm{~nm}$ so it can be argued that theoretically Otto's computational configuration is better used than the Kretschmann configuration. The use of porcine gelatin gelatin layer on the system made shows that there is a shift of SPR angle and increase of reflectance value, so that the system made can be used to detect the existence of porcine gelatin gelatin biomolecule. 


\section{CONCLUSIONS}

The results of the research can be used in the detection of porcine gelatin by Otto configurations. The best air gap thickness is $30 \mathrm{~nm}$. The best thickness of the gold layer and $\mathrm{Fe}_{3} \mathrm{O}_{4}$ layer are $50 \mathrm{~nm}$ and $0.05 \mathrm{~nm}$. The applied of MWCNT nanoparticles is not effective in the detection of biomolecules based SPR. While the thickness of SWCNT used is $1 \mathrm{~nm}$. The SWCNT material also proved to be better used in SPR systems. The addition of porcine gelatin layer in the system shows a graphic change in the form of increasing reflectance value and SPR angular shift.

\section{ACKNOWLEDGEMENTS}

This work was supported by materials team work and Computasional Laboratory department of Physics UIN Sunan Kalijaga.

\section{REFERENCES}

Arifin, M. 2009. Kajian Awal Fenomena Surface Plasmon Resonance Dalam Konfigurasi Kretschmann. (Skripsi), Universitas Gadjah Mada, Yogyakarta

Arifani, T. dan K. Abraha. 2013. Kajian Pengaruh Penambahan Nanopartikel Perak (AgNPs) Terhadap Respon Instrumen sensing berbasis Surface Plamon Resonance (SPR). Indonesian Journal of Applied Physics, 3: 47

Djurisic dan Li. 1999. Optical Constant of Carbon, (online) http://www.refractiveindex.info

Homola, J., 2006, Surface Plasmon Resonance Based Sensors, Springer, Berlin.

Husain, S., dkk. 2012. Deteksi Biomolekul dengan Menggunakan Fenomena Surface Plasmon Resonance (SPR) pada Sistem Logam/ Nanopertikel Magnetik $\mathrm{Fe}_{3} \mathrm{O}_{4}$. Prosiding Pertemuan Ilmiah XXVI HFI Jateng dan DIY
Islamiah, A R. 2016. Uji Toksisitas Akut Gelatin Babi pada Tikus Betina Galur Sprague Dawley. (Skripsi), UIN Syarif Hidayatullah, Jakarta.

Jahanshahi, Peynman dan Faisal Rafiq. 2015. Sensitivity Enhancement of Graphene-Based Surface Plasmon Resonance Biosensor Using Germanium Nanowire Grating. Medical and Bioengineering Journal, 4: 2

Kooyman, R.P.H., 2007, Physics of Surface Plasmon Resonance. Netherlands: University of Twentee, Netherlands.

Otto, A. 1968. Excitation of Nanoradiative Surface Plasma Waves in Silver by the Method of Frustrated Total Reflection. Zeitschrift for Physics, 216: 398-410

Puspitaningrum, Yanti. 2015. Deteksi DNA Gelatin Sapi dan Gelatin Babi pada Simulasi Gummy Vitamin C Menggunakan Real Time PCR untuk Analisis Kehalalan. (Skripsi), Universitas Islam Negeri Syarif Hidayatullah, Jakarta

Ru, E.C.L. dan P.G. Etchegoin, 2009, Principles of SurfaceEnhanced Raman Spectroscopy and Related Plasmonic Effects, Elsevier B.V., Amsterdam.

Sambles, J.R., G.W. Bradberry, \& F. Yang. 1991. Optical Excitation of Surtace Plasmons: an Introduction. Contemporary Physics, 32: 173-183

Sari, Rafika dan Kamsul Abraha. 2012. Simulasi Pengaruh Ketebalan Lapisan Nanopartikel Magnetik $\left(\mathrm{Fe}_{3} \mathrm{O}_{4}\right)$ terhadap Respon Biosensor Berbasis Surface Plasmon Resonance (SPR) untuk Deteksi DNA. Prosiding Pertemuan Ilmiah XXVI HFI Jateng dan DIY

Schasfoort, R.BM. dan A.J. Tudos, 2008, Handbook of Surface Plasmon Resonance, The Royal Society of Chemistry, Cambridge.

Singh, Pranveer, 2014, Nanotechnology Science and Technology: Surface Plasmon Resonance, Nove Science Publishers Inc, New York.

Wardani, D.P., dkk. 2015. Quantitative detection of Bovine and Porcine Gelatin Difference Using Surface Plasmon resonance Based Biosensor, SPIEE Proceedings, Prague

Wu, L dkk. 2010. Highly Sensitive Graphene Biosensors Based on Surface Plasmon Resonance. Optics Express, 18: 14

Yamamoto, Masahiro, 2008, Surface Plasmon Resonance (SPR) Theory: Tutorial. Kyoto University Press, Nishikyo-ku.

Yan, Huang dkk. 2013. The Determination of the Thickness and the Optical Dispersion Property of Gold Film Using Spectroscopy of a Surface Plamon in the Frequency Domain. Chin. Phys. B, 22. 